Revista de Derecho

de la Pontificia Universidad Católica de Valparaíso XXXIII (Valparaíso, Chile, ${ }^{\text {do }}$ Semestre de 2009)

[pp. 345 - 367]

\title{
LA HISTORIA DE LA CASACIÓN CIVIL ESPAÑOLA: UNA EXPERIENCIA QUE ACONSEJA NO AVANZAR EN EL MODELO DE UNIFICACIÓN DE LA DOCTRINA
}

["The History of the Spanish Civil Cassation: an Experience that Advises not to Advance in the Model of Unification of the Doctrine"]

\author{
Jordi Delgado Castro* \\ Universidad Católica de Temuco, Chile
}

\section{RESUMEN}

El presente artículo analiza la historia de la casación española. Desde su origen y planteamiento esta institución ha tenido un marcado carácter nacional que la ha distinguido de su homóloga francesa.

Un detallado repaso a la historia permite destacar las principales finalidades de la casación defensora tanto del ius litigatoris como del ius constitutionis. Sin embargo, desde las reformas de la Ley de Enjuiciamiento Civil española del año 2000 el legislador ha ido incorporando toda una serie de elementos desconocidos para el derecho español. La necesidad de descongestionar al órgano casacional español ha motivado la progresiva adopción de figuras ajenas a toda tradición anterior que rompen con las originales

\section{ABSTRACT}

This article analyses the history of the Spanish cassation. Since its origin and presentation, this institution has had a strong national feature which has differentiated it from its French counterpart.

A detailed revision of the history allows highlighting the main objectives of the cassation in relation to the defense, both ius litigatoris and ius constitutionis. However, since the reforms to the Spanish Law of Civil Procedure, carried out in the year 2000, legislators have been including a series of unknown elements to the Spanish law. In order to reduce the impediments that the Spanish cassation entity has, elements external to any former tradition have progressively been adopted, which break the original

* Doctor en Derecho por la Universidad de Barcelona, Profesor de Derecho procesal de la Escuela de Derecho de la Universidad Católica de Temuco. Dirección postal: Escuela de Derecho, Universidad Católica de Temuco, calle Manuel Montt 056, Campus San Francisco, Temuco, Chile. Dirección electrónica: jdelgado@uct.cl 
finalidades instauradas por los sabios jurisconsultos decimonónicos.

La misma senda parece estar tomando el legislador chileno. La reforma de los recursos tanto en el orden laboral como en el Proyecto de Código de Procedimiento Civil se inclina hacia un nuevo recurso de casación para la unificación de jurisprudencia no conocido en la historia chilena.

Palabras clave: Historia de la casación - Casación civil - Unificación de doctrina. objectives established by the wise jurists of the $19^{\text {th }}$ century.

The Chilean legislator seems to be walking along the same path. The reform to the recourses both in the labor law and in the Code of Civil Procedure Project goes towards a new recourse of cassation to the unification of the jurisprudence not known in the Chilean history.

KEYwORDS: History of cassation - Civil cassation - Unification of doctrine.

\section{INTRODUCCIÓN}

Las reformas de la casación en España pretenden ir alejándola de su carácter primigenio. Una correcta caracterización histórica de la casación nos mostrará cómo el legislador orienta sus últimas propuestas reformistas hacia una inevitable transformación del recurso en una institución nueva y desconocida en el derecho español.

Las pretensiones de terminar con un mal endémico propio de la casación como es el colapso del órgano encargado de la casación no debe pasar por la implantación extrema de un recurso de casación para la unificación de doctrina, ni por la adopción de toda una serie de conceptos más propios de ordenamientos anglosajones. La realidad chilena también está orientándose a la adopción de este tipo de casación.

En concreto, los artículos 483 y siguientes de la Ley No 20.260 incorporan el llamado recurso "de unificación de jurisprudencia" que pretende ser un garante de la interpretación que de la ley haga la Corte Suprema. Igual que pasara en España con el recurso de casación para la unificación de doctrina, en los procedimientos administrativo y laboral, confiamos que el legislador chileno sea más prudente, y la adopción de este tipo de modelo de recurso de "nulidad" no termine por eliminar un elemento propio y tradicional de la cultura jurídica propia chilena como es el recurso de casación.

Con una orientación similar, el Proyecto de Código Procesal Civil, también, se orienta en esta línea de regulación. En los artículos 353 y siguientes se encuentra el llamado "recurso extraordinario" cuyo objeto es la unificación de jurisprudencia con motivo de sentencias notoriamente injustas. Los escollos que debe superar este proyecto son todavía demasiados como 
para saber si se implementará, finalmente este modelo en el orden civil. Sin embargo, muestran inequívocamente que la opción del legislador chileno pasa por eliminar definitivamente la tradicional casación y sustituirla por un híbrido recurso de nulidad con un cariz anglosajón desconocido para nuestro entorno jurídico-cultural.

El estudio de la historia siempre ha facilitado la comprensión de nuestros comportamientos actuales. Es por ello que en este estudio pretendemos manifestarla como medio de denunciar el avance de un modelo reformista que se aparta diametralmente de lo que hasta hace menos de cinco años entendíamos por casación.

\section{LA HISTORIA DE LA CASACIÓN A TRAVÉS DE LA EXPERIENCIA ESPAÑOLA}

El examen del recurso de casación civil español requiere analizar tanto el origen de la casación francesa como el origen y planteamiento político de la tradicional casación española.

A la casación española se le atribuyen ${ }^{1}$, en ocasiones, antecedentes históricos o ideas inspiradoras en la supplicatio del Derecho romano de la época del Imperio o, especialmente, en la querella nullitatis del Derecho común y del Derecho estatutario italiano, cuya estructura procesal era muy similar a la del recurso de casación; pero sin embargo, pese a que se reconozcan estos precedentes, es necesario aceptar que la casación tiene un origen totalmente francés ${ }^{2}$. Así pues, es posible afirmar que su origen tiene causa en el seno de la Francia revolucionaria ${ }^{3}$.

El origen específicamente cronológico de la casación puede situarse en los Decretos de 27 de noviembre y 1 de diciembre de 1790 mediante

${ }^{1}$ VÁzQuez Sotelo, J. L., El modelo español de casación (Configuración histórica y evolución legislativa), en Scritti in onore di Elio Fazzalari (Milano, Giuffrè, 1993), p. 357. En cambio otros autores como Chiovenda, J., Principios del Derecho procesal civil (traducción de J. Casáis Santaló, Madrid, Reus, 1925), II, p. 533, habían insistido en destacar ese vínculo entre la querella nullitatis y el recurso de casación como medios de garantizar la exacta observancia de la ley conjugando la defensa tanto del ius litigatoris como del ius constitutionis.

${ }^{2}$ Nieva Fenoll, J., El recurso de casación civil (Ariel, Barcelona, 2003), p. 24.

${ }^{3}$ GÉNY, F. Método de interpretación y fuentes en Derecho privado positivo (Madrid, Reus, 1925), p. 74; Gómez Orbaneja, E. - Herce Quemada, V., Derecho procesal civil (Madrid, Artes Gráficas y Ediciones, 1979), p. 482; MonTero ArocA, J. - FlorS Matíes, J., Los recursos en el proceso civil (Valencia, Tirant lo Blanch, 2001), p. 553; Ortells Ramos, M., Derecho jurisdiccional (Pamplona, Aranzadi, 2004), p. 579; VÁzquez Sotelo, J. L., El modelo español, cit. (n. 1), pp. 357-358. 
los que se creó el Tribunal de Cassation ${ }^{4}$. La creación de este órgano, sin duda, constituye una de las principales y más valiosas aportaciones hechas al mundo jurídico por la Revolución francesa ${ }^{5}$.

En concreto, tres serán los factores determinantes en el nacimiento de la casación. En primer lugar, el concepto "ley" se convierte en uno de los principales ejes sobre los que gira la doctrina revolucionaria. La idea central es que los ciudadanos se someten libre y voluntariamente a la ley que ellos mismos otorgan ${ }^{6}$ y de ahí que se plantee la necesidad de articular una vigilancia ${ }^{7}$ sobre el correcto uso de la voluntad del pueblo soberano y una igual aplicación de la ley para todos ${ }^{8}$, a través de la creación de un órgano que con un criterio único mantuviese a los jueces dentro de los límites permitidos por la ley.

En segundo lugar, adquirirá capital importancia la creencia en el modelo de separación de poderes ${ }^{9}$. El nuevo régimen consideró del todo necesario evitar injerencias entre los distintos poderes del Estado. En especial se quiso evitar a toda costa que el Poder judicial invadiese el campo del Poder legislativo. El modelo revolucionario francés aboga por otorgar la soberanía al pueblo y ésta se manifiesta mediante el Poder legislativo. El cometido del órgano jurisdiccional era buscar las consecuencias que la ley preveía aplicables al caso particular de una forma automática, sin entrar en interpretaciones o precisiones doctrinales ${ }^{10}$. Tanto fue así que se consideraba que si en algún caso había que interpretar la ley, ello era labor propia del Poder legislativo, bien fuera mediante el uso facultativo por parte del juez del "référé législatif", bien fuese mediante el "référé obligatoire au législateur". La prohibición de "interpretar" impuesta a los

${ }^{4}$ Fernández, M. A., Derecho procesal civil (con de la Oliva, J., Madrid, Centro de Estudios Ramón Areces, 1995), II, p. 559.

${ }^{5}$ Calamandrei, P. La casación civil (traducción de Sentís Melendo, Buenos Aires, 1945), I, 2, p. 15.

${ }^{6}$ Rousseau, J. J. El contrato social (traducción de J. Carrier, Barcelona, Edicomunicación, 1994), p. 63. Esta idea queda, además, manifiestamente expresada en el artículo 6 de la Declaración de Derechos del Hombre y el Ciudadano de 26 de agosto de 1789: "la ley es la expresión de la voluntad general y debe ser la misma para todos tanto si protege como si castiga".

${ }^{7}$ Gomez Orbaneja, E. - Herce Quemada, V. Derecho procesal civil, cit. (n. 3), p. 482.

${ }^{8}$ Martínez-Calcerrada y Gómez, L. La nueva casación civil. Estudio de la Ley 10/1992 de 30 de abril (Madrid, Civitas, 1993), p. 45.

${ }^{9}$ Montesquieu, Ch. L., Del espíritu de las leyes (traducción de M. Blázquez y P. de Vega, Madrid, Sarpe, 1984), I, p. 169.

${ }^{10}$ Morello, A. M., La casación. Un modelo eficiente (La Plata, Librería Editora Platense, 2000), p. 7. 
diferentes órganos jurisdiccionales pretendía, a su vez, evitar las injusticias que se habían sucedido mediante las disquisiciones hechas por los jueces del Ancien Régime.

Finalmente, en tercer lugar, debemos destacar la gran influencia adquirida y derivada de la experiencia histórica. Las instituciones del Antiguo Régimen eran conocidas por los creadores de la casación revolucionaria y, pese al ánimo de romper con las mismas, es innegable su influencia.

La experiencia adquirida durante la división feudal de Francia en Parlamentos contribuyó a la instauración, desde la Ordenanza de 23 de marzo de 1302 de un órgano de control único que desde las altas esferas del Estado controlase el literal cumplimiento de la ley por parte de los órganos jurisdiccionales (Requêtes de l'Hostel du Roy) ${ }^{11}$. Con esta idea de vigilancia y, sirviendo a un interés más bien político, en defensa de los intereses del monarca contra el poder de los Parlaments ${ }^{12}$, se creó una sección del Consejo de Estado que atendía las quejas de los particulares cuando consideraban que la decisión de uno de los Parlaments era contraria a una ordenanza real: el Conseil des Parties.

De aquella experiencia previa, ante el temor de que los órganos jurisdiccionales transgrediesen el derecho objetivo bajo el pretexto de interpretarlo, desempeñando funciones correspondientes al Poder legislativo ${ }^{13} \mathrm{y}$ tratando de evitar los excesos cometidos por los jueces durante el antiguo régimen, la Asamblea crea el Tribunal de Cassation. Este nuevo órgano nace con la vocación de mantener y cuidar la observancia de la ley ${ }^{14}$ y la separación de poderes (en especial se cuidará de vigilar las relaciones entre el legislativo y el judicial).

El objetivo de la Corte de Casación era evitar que los pronunciamientos de los jueces se transformasen en disposiciones de carácter general y abstracto desembocando en leyes ${ }^{15}$.

La evolución, en términos generales, de la casación francesa culminará con las leyes de 1 de abril de 1837 y de 7 de noviembre de 1979, que termi-

${ }^{11}$ Guasch Fernández, S., El hecho y el Derecho en la casación civil (Barcelona, Bosch, 1998), p. 33.

${ }^{12}$ Prieto-Castro, L., Tratado de Derecho procesal civil (Pamplona, Aranzadi, 1985), II, p. 470.

${ }^{13}$ Moreno Catena, V., Los recursos extraordinarios por infracción procesal y casación, en Gimeno Sendra, V. - Moreno Catana, V. - Cortés Domínguez, V., Derecho procesal civil. Parte general (2a edición, Madrid, Colex, 2003), p. 402.

${ }^{14}$ Tovar Morais, A., El recurso de casación civil (Ley 6 de agosto de 1984) (Pamplona, Aranzadi, 1985), p. 20.

${ }^{15}$ Calamandrei, P., La casación civil, cit. (n. 5), I, 2, p. 41; Gómez Orbaneja, E. - Herce Quemada, V., Derecho procesal civil, cit. (n. 3), p. 482: "para impedir que los jueces, subrepticiamente, hicieran obra de legisladores". 
naron de reformar el mecanismo del reenvío ${ }^{16}$. De este modo, el recurso de casación se transformará en un recurso de corte jurisdiccional. El objetivo principal del recurso será la tutela de los derechos de los litigantes y, además, se instruirá en un elemento uniformador en la interpretación y aplicación del derecho por parte de los diferentes órganos jurisdiccionales ${ }^{17}$.

Así pues, podemos concluir que la Corte de Casación vino configurada como un órgano eminentemente político, que nace con la finalidad de velar por la integridad de la ley y con la misión de anular las posibles interpretaciones erróneas, y contrarias a la ley, que pudiesen cometer los órganos jurisdiccionales ${ }^{18}$. Era un órgano, adjunto a la Asamblea Legislativa, que desarrolló la función de anular o rescindir las sentencias que los jueces franceses dictasen contraviniendo lo dispuesto por la ley ${ }^{19}$.

Por su parte, la tradicional casación española dista mucho desde su origen a la casación francesa ${ }^{20}$. La casación española destaca por una conformación histórica que la hace demostrar una acusada personalidad propia, hasta el extremo de que parte de la mejor doctrina española la llega a calificar de "casación nacional" 21 . La principal nota característica propia de la tradicional casación española es que, desde su origen, nace como un recurso jurisdiccional ${ }^{22}$.

${ }^{16}$ Sobre el régimen y funciones actuales de la casación en Francia, véanse, por todos: Bachellier, X., La technique de cassation (París, Dalloz, 2003); Boré, J. L., La cassation en matière civile (París, Dalloz, 2003); y CADIET, L., El sistema de la casación francesa, en ORTELLs Ramos (coordinador), Los recursos ante los Tribunales Supremos en Europa / Appeals to Supreme Courts in Europe. Coloquio de Gandia y Valencia, 6, 7 y 8 de noviembre de 2008 (Madrid, Difusión Jurídica y Temas de Actualidad, 2008).

${ }^{17}$ Vallespín Pérez, D., El papel de los tribunales superiores de justicia ante la casación civil, en Justicia 3-4 (2005), p. 36.

${ }^{18}$ Serra Domínguez, M., El recurso de casación en la LEC 1/2000, en Revista Jurídica de Catalunya 4 (2001), p. 1.137.

${ }^{19}$ Calamandrei, P., La casación civil, cit. (n. 5), I, 2, pp. 40 ss.

${ }^{20}$ VázQuez Sotelo, J. L., La casación civil (revisión crítica) (Barcelona, Ediser, 1979), p. 14; Morón Palomino, M., Precisiones y significación constitucional del recurso de casación, en Diario La Ley 5 (2004), p. 1,425.

${ }^{21}$ Fairén Guillén, V., La doctrina legal y el control de los hechos en la casación civil y laboral española, en Temas del ordenamiento procesal (Madrid, Tecnos, 1969), II, p. 1.207; Morón Palomino, M., La nueva casación civil (Madrid, Colex, 2001), p. 41; Nieva Fenoll, J., El recurso de casación civil, cit. (n. 2), p. 28; VÁzQuez Sotelo, J. L., Rasgos definidores de la casación civil española, en Revista de Derecho Procesal (1974), p. 859.

${ }^{22}$ La casación francesa nació motivada por razones políticas, mientras la casación española, ya desde sus orígenes, se enmarca en el plano jurisdiccional. En este sentido: Garberí llobregat, J. - González-Cuéllar Serrano, N., Apelación y casación 
La función del recurso de casación español destaca tanto por ser un mecanismo defensor del ius constitutionis ${ }^{23}$ (función nomofiláctica, de protección y salvaguarda de la norma; y función uniformadora de la jurisprudencia en la interpretación y aplicación del derecho objetivo); como del ius litigatori ${ }^{24}$, es decir, al derecho de los litigantes, pues no conviene olvidar que la unificación de la jurisprudencia es sólo un bien en tanto que posibilita a los ciudadanos conocer de antemano, con cierta seguridad, la regla de juicio que les será aplicada en una eventual controversia ${ }^{25}$.

En todo recurso del tipo de la casación se ha considerado importante que el órgano jurisdiccional garantice la uniformidad de la jurisprudencia, sin embargo el clásico recurso de casación español utiliza esta premisa como medio a través del cual alcanzar la protección del ordenamiento jurídico ${ }^{26}$. El órgano de casación conseguirá una mejor protección del ordenamiento jurídico cuantos más sean los casos concretos que resuelva, conjurando de este modo las interpretaciones discrepantes con dicho ordenamiento jurídico ${ }^{27}$. Por ello, resulta fundamental proteger el derecho propio del simple ciudadano de a pie (ius litigatoris) ${ }^{28}$.

La introducción de la casación en España obedeció, tanto al afrancesa-

en el proceso civil (Madrid, Colex, 1994), p. 170; Moreno CATEna, V., Los recursos extraordinarios, cit. (n. 3), p. 403; Vallespín Pérez, D., El papel de los tribunales superiores ante la casación civil, en GIMENO SENDRA, V. (coordinador), El Tribunal Supremo, su doctrina legal y el recurso de casación, en Estudios en Homenaje del Profesor Almagro Nosete (Madrid, Iustel, 2007), p. 534; VÁzQuez Sotelo, J. L., La casación civil (revisión crítica), cit. (n. 20), p. 14. En contra de esta opinión, opina por un origen, igual al francés, de tipo político: Vicente Chamorro, J., El recurso de casación en materia civil (Pamplona, Aranzadi, 1991), p. 35. En una postura ecléctica, en atención al beneficiario de las consecuencias jurídicas de la casación, se encuentra DE La Plaza, M., Derecho procesal civil español, en Revista de Derecho Privado 1 (Madrid 1951), p. 629, cuando afirma que el recurso de casación está dotado de un contenido jurisdiccional respecto de las partes $\mathrm{y}$, a su vez, de un contenido político en relación con el Estado.

${ }^{23}$ Martínez-Calcerrada y Gómez, L., La nueva casación civil. Estudio de la ley 10/1992, de 30 de abril, cit. (n. 8), p. 47.

${ }^{24}$ VÁzquez Sotelo, J. L., Rasgos definidores de la casación civil española, cit. (n. 21), p. 925.

${ }^{25}$ Guasch Fernández, S., El hecho y el Derecho en la casación civil, cit. (n. 11), p. 39.

${ }^{26}$ JimÉNEZ Fortea, F. J., El recurso de casación para la unificación de la doctrina laboral: problemas fundamentales (Valencia, Tirant lo Blanch, 1999), p. 50.

${ }^{27}$ Nieva Fenoll, J., La casación en materia social ("ordinaria" y por unificación de doctrina): la decadencia de la casación, en Relaciones Laborales 15-16 (2004), p. 563.

${ }^{28}$ Martínez Emperador, R., La nueva casación social. Puntos críticos, en Actualidad Laboral 16 (1992), p. 294. 
miento propio del siglo XIX ${ }^{29}$, que terminó por afectar al terreno judicial, como a la necesidad, reconocida por el legislador, de reordenar el sistema de recursos que se había transformado en algo extremadamente complejo.

Sin perjuicio de otros precedentes ${ }^{30}$, la casación española encuentra su primer antecedente en el Real Decreto de 4 de noviembre de $1838^{31}$, sobre el recurso de nulidad por infracción de "ley o doctrina legal". Este recurso de nulidad nace con la finalidad de derogar los recursos de injusticia notoria y de segunda suplicación. Además, con esta reforma se posibilitó una mejor organización de los trámites de enjuiciamiento de los recursos de nulidad contra los fallos de las Reales Academias y del Tribunal de Guerra y de Marina.

El recurso de nulidad es un recurso de casación, que prevé motivos tanto in iudicando como in procedendo pero limitándolos numéricamente y articulándose un sistema de reenvío ${ }^{32}$ al tribunal a quo. El órgano jurisdiccional a quo debe dictar una nueva sentencia o, en su caso, debía reponer los autos al momento en que se produjo el vicio procesal determinante de la nulidad.

Existen tres momentos legislativos que determinaron un gran impulso al asentamiento del recurso de casación y que, sin duda, contribuyeron a su desarrollo. En primer lugar, el Real Decreto de 1852, de 20 de junio, que tuvo la trascendencia de utilizar, por vez primera, el término "casación"

${ }^{29}$ Nieva Fenoll, J. El recurso de casación civil, cit (n. 2), p. 28.

${ }^{30}$ Algunos autores, como: Gómez Orbaneja, E. - Herce Quemada, V., Derecho procesal civil, cit. (n. 3), p. 484; Manresa y NaVArRo, J. M. Comentarios a la Ley de Enjuiciamiento Civil (Madrid, Instituto Editorial Reus, 1895), VII, p. 525; MARTíNeZ-Calcerrada y GÓmez, L., La nueva casación civil. Estudio de la ley 10/1992, de 30 de abril, cit. (n. 8), p. 45; TOVAR MoraIs, A. El recurso de casación civil (Ley 6 de agosto de 1984), cit. (n. 14), p. 20; Vicente ChAmorro, J., El recurso de casación en materia civil, cit. (n. 22), p. 35, han considerado que el precedente de la casación española cabe individualizarlo en el llamado recurso de nulidad introducido por las Cortes de Cádiz en 1812. Sin embargo, en sentido estricto no puede afirmarse que la casación haya nacido en España con la Constitución de Cádiz. Ello es así, porque el recurso de nulidad se asemeja más bien a una querella nullitatis, cuyo único y exclusivo objeto venía constituido por algunos defectos de forma.

${ }^{31}$ Serra Domínguez, M., El recurso de casación en la LEC 1/2000, cit. (n. 18), p. 1.139.

${ }^{32}$ La experiencia determinaría la elección de un sistema diferente al adoptado por el modelo francés. Así, los proyectos de Ley de Enjuiciamiento Civil de 1840 (García Gallardo) y 1841 (Gómez Becerra) desecharon la técnica del reenvío y otorgaron al Tribunal Supremo la obligación de pronunciarse sobre el fondo del asunto. Pese a que ninguno de estos proyectos se materializó, sí fue determinante su influencia en el Real Decreto de 20 de junio de 1852, que materializó en una ley positiva estas consideraciones. 
y, además, suprimió el sistema de reenvío de los autos a la Audiencia. En segundo término, es de destacar la llamada "Instrucción del Marqués de Gerona", de 1853, que introdujo aspectos como el impulso de oficio, el principio de concentración o el de publicidad. Finalmente, la Real Cédula, de 30 de enero de 1855, para la Administración de Ultramar sentaría las bases de consolidación de la casación y generalizaría su uso.

Además de esos tres hitos históricos es necesario destacar la importancia de la Ley de Enjuiciamiento Civil de 1855. Ésta incorporó la regulación de un recurso de casación que podía fundarse tanto en motivos in iudicando como in procedendo, y cuya jurisprudencia tenía una clara vocación nomofiláctica ${ }^{33}$.

Poco después, podemos hablar de un recurso de casación consolidado y muy al uso. El resultado de la utilización de este mecanismo de impugnación determina -constante histórica de este recurso- el colapso del Tribunal Supremo. Así, con el objetivo de reducir la carga de trabajo del Tribunal Supremo como consecuencia del gran número de recursos de casación que fueron interpuestos, se publicaron distintas leyes dirigidas con carácter específico a regular la casación: la Ley de 30 de abril de 1864, que contemplaba una nueva organización de las Salas del Tribunal Supremo; la Ley provisional de 18 de junio de 1870, de reforma de la casación civil; y la Ley de 22 de abril de 1878, de casación civil.

La Ley de Enjuiciamiento Civil de 1855, con las modificaciones de la Ley de casación de 1878, fue la mayor fuente de inspiración en la creación del recurso regulado por la Ley de Enjuiciamiento Civil de 1881, a través de la Ley de Bases de 21 de junio de 1880. El legislador realizó la distinción entre la casación por infracción de ley o doctrina legal (artículo 1692) y la casación por quebrantamiento de las formas esenciales del juicio (artículo 1693), sin prestar atención a la calificación dogmática de cada defecto, sino fijándose tan sólo en la necesidad o no de la derivación al mecanismo del reenvíio ${ }^{34}$.

La práctica forense determinó la necesidad de que, unos años después,

${ }^{33}$ Fairén Guillén, V., Estudio externo de la Ley de Enjuiciamiento Civil de 1855, en Temas del ordenamiento procesal (Madrid, Tecnos, 1969), II, pp. 19 ss.; MaNRESA, J. M., Observaciones sobre el recurso de casación en España, en Revista General de Legislación y Jurisprudencia 16 (1960), pp. 257 ss.; Montero Aroca, J., La Ley de Enjuiciamiento Civil de 1855. La consolidación del proceso común, en Ensayos de Derecho procesal (Barcelona, Bosch, 1996), pp. 169 ss.; Morón Palomino, M., La nueva casación civil, cit. (n. 23), pp. 49 ss.; Nieva FenOlL, J., El recurso de casación civil, cit. (n. 2), pp. 31 ss.; VÁzQUez Sotelo, J. L., Rasgos definidores de la casación civil española, cit. (n 21), pp. 14 ss.

${ }^{34}$ Nieva Fenoll, J., El recurso de casación civil, cit. (n. 2), p. 34. 
se reformara el recurso. Así, se promulgó la Ley de 23 de julio de 1966. De un lado, se suprime el recurso para las sentencias dictadas por los jueces de primera instancia en los juicios de desahucio que conocieran en apelación. De otro, se suprime el apuntamiento tanto en los recursos de apelación como de casación.

Sin duda una de las reformas de mayor importancia fue la reforma urgente de la Ley de Enjuiciamiento Civil, a través de la Ley No 34/1984, de 6 de agosto, en la que siguen apreciándose los principios informadores de la casación española que cabía observar en la Ley de Enjuiciamiento Civil (LEC.) de $1881^{35}$. Esta reforma respondió a necesidades prácticas muchas veces contrapuestas entre sí: de un lado, la necesaria uniformidad de la jurisprudencia, conjugada con la concesión a los ciudadanos de un último y definitivo recurso jurisdiccional; y, de otra, la necesidad de restringir el acceso a la casación para garantizar la seguridad jurídica y evitar la incertidumbre derivada del retraso en la declaración definitiva del derecho en lo concreto ${ }^{36}$.

La reforma de 1984 procedió a una nueva ordenación de la casación y consagró la implantación de una única tramitación a nivel procedimental, con independencia de si el recurso lo era por vicios in iudicando o por vicios in procedendo ${ }^{37}$. Sin duda, una de las novedades más importantes de la nueva regulación consistió en que todos los motivos de casación se vieron agrupados en los cinco motivos del nuevo artículo 1692 LEC. El motivo quinto (error en la apreciación de la prueba), el de más amplio espectro, permitirá flexibilizar las restricciones de acceso al recurso ${ }^{38}$.

La reforma de 1984, por lo tanto, fue considerada un avance y supuso

${ }^{35}$ Entre otros, véanse: De CASTRo Fernández, J., La reforma de la casación, en Revista Jurídica de Catalunya 4 (1985), p. 7; Fernández RodríGuez, A., La nueva ordenación de los recursos. Especial estudio del recurso de casación, en Jornadas sobre la Reforma de la Ley de Enjuiciamiento Civil (Madrid, Consejo General del Poder Judicial, 1985), p. 384; Puignaire Hernández, J. M., Comentarios a la Ley de reforma urgente del procedimiento civil (Barcelona, Acervo, 1985), p. 19; SANTOS BRIZ, J., El recurso de casación. Su reforma por Ley 34/1984, de 6 de agosto, e incidencia de la misma en las reclamaciones derivadas de accidentes de circulación, en Revista de Derecho Privado (1985), p. 827.

${ }^{36}$ Serra Domínguez, M. El recurso de casación, en El mismo (coordinador), Comentarios a la reforma de la Ley de Enjuiciamiento Civil (Ley 34/1984, de 6 de agosto) (Madrid, 1985), p. 783.

${ }^{37}$ Montero Aroca, J. - Flors Matíes, J., Los recursos en el proceso civil (Valencia, Tirant lo Blanch, 2001), p. 553.

${ }^{38}$ Peces Morate, J. E., La jurisprudencia como guía y modelo en la función de juzgar, en Gimeno SEndra, V. (coordinador), El Tribunal Supremo, su doctrina legal y el recurso de casación. Estudios en Homenaje al Prof. Almagro Nosete (Madrid, Iustel, 2007), p. 410. 
un estimable progreso desde la perspectiva de la mejor defensa del justiciable. La siguiente etapa en la historia de la casación está determinada por la promulgación de la Ley No 10/1992, de 30 de abril, de Medidas Urgentes de Reforma Procesal, que resultó claramente "involutiva" 39 o "regresiva" ${ }^{4}$.

El principal inconveniente que plantea esta reforma está en su origen y finalidad. La inspiración de la norma se fija, principalmente, en criterios de orden práctico, claramente orientados a la descarga de trabajo de la sala $1^{\text {a }}$ del Tribunal Supremo ${ }^{41}$. Por ese motivo, se adoptarán medidas como eliminar el error de hecho en la apreciación de la prueba documental. ${ }^{42}$

Entre sus novedades, destaca la unificación de motivos recogida por el artículo 1692 LEC., así como la unificación del procedimiento. Pero a pesar de esa apariencia, continuaba siendo posible distinguir entre casación por infracción de ley y, casación por quebrantamiento de forma ${ }^{43}$. Distinción que se infiere de los distintos efectos que produce la sentencia estimando el recurso en un sentido u otro: la casación por infracción de ley resolverá sobre el fondo del asunto sustituyendo la decisión del órgano de instancia $y$, por su parte, la casación por quebrantamiento de forma devolverá el procedimiento al órgano jurisdiccional cuyo fallo ha sido anulado, a fin de que subsane su error y continúe su tramitación ${ }^{44}$.

Lamentablemente, además, se demostró que las medidas encaminadas a la descarga de trabajo del Tribunal Supremo aumentaron los retrasos entre la interposición y resolución del recurso. Se limitó en exceso la recurribilidad de las resoluciones y se dotó de menor valor a la autoridad de la jurisprudencia, cuyo resultado derivó en constantes contradicciones en la sala $1^{\mathrm{a}}$.

El año 2000 una gran reforma procesal ocurrió en España. La Ley de Enjuiciamiento Civil de 2000 optó por la consagración de un "sistema"

${ }^{39}$ VÁzquez Sotelo, J. L., El modelo español de casación, cit. (n. 1), p. 411.

${ }^{40}$ Morón Palomino, M., La nueva casación civil, cit. (n. 23), p. 63.

${ }^{41}$ Ortells Ramos, M., Derecho jurisdiccional, cit. (n. 3), p. 582; El mismo, La selección de asuntos para su acceso a la casación en Derecho Español: Las técnicas de "unificación de doctrina" y de "interés casacional", en Ortells Ramos, M. (coordinador), Los recursos ante los Tribunales Supremos en Europa / Appeals to Supreme Courts in Europe. Coloquio de Gandia y Valencia, 6, 7, y 8 de noviembre de 2008 (Madrid, Difusión Jurídica y Temas de Actualidad, 2008).

${ }^{42}$ Afortunadamente, la propia "práctica" le dio la vuelta a esa circunstancia y recondujo esa limitación al error de Derecho. Véase: Ramos Méndez, F., Enjuiciamiento civil (Barcelona, Bosch, 1997), p. 559.

${ }^{43}$ Nieva Fenoll, J., El recurso de casación civil, cit. (n. 2), p. 37.

${ }^{44}$ Vázquez Sotelo, J. L., El modelo español, cit. (n. 1), pp. 413-414. 
de casación desconocido tanto en el derecho histórico español, como en los ordenamientos procesales civiles del entorno cultural ${ }^{45}$.

La regulación procesal civil del año 2000 distingue entre un recurso extraordinario por infracción procesal (artículos 468 ss.) y un recurso de casación (artículo 477 ss.). El primero, el recurso extraordinario por infracción procesal es el heredero del antiguo recurso de casación por quebrantamiento de forma, que procede contra aquellas sentencias y autos dictados por las Audiencias Provinciales en apelación, por los motivos taxativamente fijados por la Ley. Se pretende que las salas de lo civil y penal de los tribunales superiores de justicia controlen la regularidad y validez de la actuación procesal desempeñada y el cumplimiento de la normativa que rige los actos y garantías procesales, anulando dichas resoluciones si se han quebrantado.

El recurso de casación, cuyo conocimiento se atribuye a la sala $1^{\text {a }}$ del Tribunal Supremo y, excepcionalmente, a las salas de lo civil y penal de los tribunales superiores de justicia, está pensado para interponer contra las sentencias dictadas en segunda instancia por la Audiencia para la tutela judicial civil de los derechos fundamentales excepto los que reconoce el artículo 24 de la Constitución Española; cuando la cuantía del asunto excede de 150.000 euros; y cuando la resolución del recurso presente interés para la casación ${ }^{46}$.

${ }^{45}$ Por su parte, JimÉnez ForteA, La casación para la unificación de doctrina laboral: instituciones afines en Derecho comparado, en Revista General de Derecho 649650 (1998), pp. 12.763-12.778, encontró ciertos paralelismos entre el recurso de casación para unificación de la doctrina y el artículo 374,II. del Codice di Procedura Civile y, también, la "Divergenzrevision" alemana.

${ }^{46}$ Para un análisis de estos recursos extraordinarios, véanse, por todos: GIMENO Sendra, V., El recurso extraordinario por infracción procesal, en PiCó I JunOY (director), Presente y futuro del proceso civil (Barcelona, Bosch, 1998), p. 305 ss.; GIMENO SENDra, V. (coordinador), El recurso civil de casación, el Tribunal Supremo, su doctrina legal y el recurso de casación, en GIMENO SENDRA, V. (coordinador), Estudios en Homenaje del Profesor Almagro Nosete (Madrid, Iustel, 2007), p. 208 ss.; MálagA DíEGUEZ, F., Los recursos de casación y extraordinario por infracción procesal en la jurisprudencia del Tribunal Superior de Justicia de Cataluña, en Justicia 1-3 (2003); Morón Palomino, M., La nueva casación civil, cit. (n. 23); Nieva Fenoll, J., El recurso de casación civil, cit. (n. 2), pp. 35 ss.; Ortells Ramos, M., El Tribunal Supremo Español: Un Tribunal en busca de identidad, en Gimeno Sendra, V. (coordinador), El Tribunal Supremo, su doctrina legal y el recurso de casación. Estudios en Homenaje del Profesor Almagro Nosete (Madrid, Iustel, 2007), pp. 555 ss.; Peces Morate, J. E., La jurisprudencia como guía, cit. (n. 38), pp. 420 ss.; Ramos Méndez, F., ¿Qué hacemos con el Tribunal Supremo? en GiMENO SENDRA, V. (coordinador), El Tribunal Supremo, su doctrina legal y el recurso de casación. Estudios en Homenaje del Profesor Almagro Nosete (Madrid, Iustel, 2007), pp. 364 ss.; Rodríguez Bahamonde, R., El 
Esta regulación "bifronte" de los recursos extraordinarios en la nueva Ley de Enjuiciamiento Civil no sólo es poco práctica, dado que es fácil que en una cuestión de casación se vinculen vicios in iudicando con otros in procedend $o^{47}$, sino que también puede reputarse como inconstitucional. Ello obedece básicamente a dos grandes argumentos: En primer lugar, conculca las potestades jurisdiccionales del Tribunal Supremo ${ }^{48}$. Por otra parte, atribuye a los tribunales superiores de justicia la resolución de los recursos extraordinarios por infracción procesal, lo cual provoca en la práctica el desamparo tanto de la seguridad jurídica como de la igualdad en la aplicación de la ley material ${ }^{49}$ ya que debido al condicionamiento de la utilización de los recursos, obligando al litigante a optar por una u otra impugnación, se provoca una clara vulneración del derecho de defensa de la parte ${ }^{50}$.

Sin embargo, y pese a que esa reforma del año 2000 fue criticada por la gran mayoría de la doctrina, esa crítica se diluyó por la gran cantidad de aciertos, en especial la introducción de la oralidad al proceso civil, en

recurso extraordinario por infracción procesal, en AlONSO-CuEvillas (coordinador), Instituciones del nuevo proceso civil. Comentarios sistemáticos a la Ley 1/2000 (Barcelona, Economist \& Jurist, 2000), pp. 192 ss.; Serra Domínguez, M., El recurso de casación en la LEC 1/2000, cit. (n. 18), pp. 1.137 ss.; y VALLESPín Pérez, D., El papel de los Tribunales Superiores de Justicia ante la casación civil, en Gimeno Sendra, V. (coordinador), El Tribunal Supremo, su doctrina legal y el recurso de casación. Estudios en Homenaje del Profesor Almagro Nosete (Madrid, Iustel, 2007), pp. 533 ss.

${ }^{47}$ Almagro Nosete, J., Situación de la casación civil en España, en Ortells Ramos, M. (coordinador), Los recursos ante los Tribunales Supremos en Europa / Appeals to Supreme Courts in Europe. Coloquio de Gandia y Valencia, 6, 7, y 8 de noviembre de 2008 (Madrid, Difusión Jurídica y Temas de Actualidad, 2008); Muñoz Jiménez, F. J., Del recurso de casación por infracción procesal, en Comentarios a la nueva Ley de Enjuiciamiento Civil, II, p. 2.208.

${ }^{48}$ Gimeno Sendra, V., El recurso extraordinario por infracción procesal, cit. (n. 46), pp. 308 ss.; SaAvedra Gallo, P., Comentario al artículo 466 de la nueva LEC, en Gómez de Liaño, F. (coordinador), Ley de Enjuiciamiento Civil (Ley 1/2000) (Oviedo, Forum, 2000).

${ }^{49}$ Gimeno Sendra, V., El recurso de amparo judicial y el anteproyecto de Ley de Enjuiciamiento Civil, en Diario La Ley 6 (1997) D.310, p. 1441; Morales Morales, F., El recurso extraordinario por infracción procesal, Diario La Ley 5 (2001) D.149, p. 1.651 .

${ }^{50}$ Gimeno Sendra, V., El recurso civil de casación, en Gimeno Sendra, V. (coordinador), El Tribunal Supremo, su doctrina legal y el recurso de casación. Estudios en Homenaje del Profesor Almagro Nosete (Madrid, Iustel, 2007), p. 229; VAlLESPín PÉREZ, D. El modelo constitucional de juicio justo en el ámbito del proceso civil (Barcelona, Atelier, 200), p. 46; El MISMO, Los nuevos retos del derecho a la tutela judicial efectiva en el proceso civil (Barcelona, Cims Editorial, 2009). 
otras materias en que cayó el legislador de la llamada "nueva Ley de Enjuiciamiento Civil'.

Pese a todo, la casación civil española siempre ha demostrado una identidad propia y duradera que se ha ido manteniendo desde su origen. El principal problema se avecina con las reformas futuras. De este modo, dos anteproyectos de ley de $2005^{51}$ volvieron a abrir el camino de la reforma de la casación ${ }^{52}$. Ambos proyectos, con el acierto de suprimir el recurso extraordinario por infracción procesal ${ }^{53}$, pretendían, una vez más, atenuar el colapso que sufre la sala $1^{\text {a }}$ del Tribunal Supremo ${ }^{54}$. El modo que el

${ }^{51}$ Anteproyectos cuyo informe fue aprobado por el Consejo de Ministros en la reunión de 15 de julio de 2005: "Anteproyecto de Ley Orgánica por la que se modifica la Ley No 6/1985, de 1 de julio, del Poder Judicial, en materia de organización territorial de la Administración de Justicia, a los efectos previstos en el artículo 22,3 de la Ley No 50/1997, de 27 de noviembre, del Gobierno" (Proyecto de Ley Orgánica, de 27 de enero de 2006, aprobado el 16 de diciembre de 2005); y "Anteproyecto de Ley por el que se modifica la Ley de Enjuiciamiento Criminal, la Ley 29/1998, reguladora de la Jurisdicción Contencioso-Administrativa, y la Ley 1/2000, de Enjuiciamiento Civil, en materia de recursos de casación, de doble instancia penal y de justicia de proximidad, a los efectos previstos en la Ley 50/1997, de 27 de noviembre". Ambos Anteproyectos, que llegaron a ser objeto de enmiendas, ante la inminencia de la que ya es la nueva Legislatura -iniciada en 2008- están caducados y a la espera de su reactivación o sustitución.

${ }^{52}$ El camino de esta reforma comenzó a fraguarse con el "Pacto de Estado para la Reforma de la Justicia”, suscrito por el Partido Popular y el Partido Socialista Obrero Español, el 28 de mayo de 2001, y en el que, entre otros extremos, se acordó que: "se afrontarán las reformas necesarias para lograr un funcionamiento más ágil y eficaz del Tribunal Supremo y que potencien su función como órgano jurisdiccional superior y garante de la unidad de doctrina en todos los órdenes jurisdiccionales. A tal fin, también se reformará el recurso de casación, aproximando su regulación en las diferentes leyes reguladoras del proceso y atendiendo a la noción del "interés casacional".

${ }^{53}$ Gimeno Sendra, V., derecho procesal Civil, I: El Proceso de declaración. Parte general (Madrid, Colex, 200), pp. 617-618.

${ }^{54}$ García CelaÁ, B., El principio de unidad jurisdiccional. Las reformas en el recurso de casación, los consejos territoriales y la justicia de proximidad en relación con la jurisdicción social, en Estudios de Derecho Judicial 90 (2006): Poder Judicial y unidad jurisdiccional en el Estado autonómico, p. 231; GIMENO SENDRA, V., El recurso español de casación civil: Perspectiva de Reforma, en OrTells Ramos, M. (coordinador), Los recursos ante los Tribunales Supremos en Europa / Appeals to Supreme Courts in Europe. Coloquio de Gandia y Valencia, 6, 7, y 8 de noviembre de 2008 (Madrid, Difusión Jurídica y Temas de Actualidad, 2008); SÁnchez Albarrán, O., La eficiencia de la futura reforma de la casación civil española. Una aproximación desde la óptica del análisis económico del derecho, en Revista Vasca de Derecho Procesal y Arbitraje 3 (2007), p. 396. Problema que, además de constante en nuestras reformas procesales, es común a nuestro entorno cultural. En orden al análisis de esta constante en Alemania, véase: GotTWALD, P., El recurso ante el Tribunal Supremo Federal alemán tras la reforma de 
legislador español encuentra para cumplir este cometido es: aumentar las competencias de los tribunales superiores de justicia de las Comunidades Autónomas ${ }^{55}$, de una parte, y reformar el tradicional recurso de casación y transformarlo en un "recurso para unificación de doctrina" 56 .

Con estas modificaciones se intenta exportar al orden civil la experiencia de la sala de lo social del Tribunal Supremo, con claro olvido de que la limitación de la viabilidad de los recursos en atención a la exigencia de contradicción jurisprudencial, tal y como ha sido interpretada por la sala $4^{\mathrm{a}}$, termina por conculcar el acceso al recurso ${ }^{57}$.

La concesión de mayor protagonismo a los tribunales superiores de justicia, que podría haberse llevado a cabo con otras opciones legislati-

2001 (versión abreviada), en ORTELLs RAmOs, M. (coordinador), Los recursos ante los Tribunales Supremos en Europa / Appeals to Supreme Courts in Europe. Coloquio de Gandia y Valencia, 6, 7, y 8 de noviembre de 2008 (Madrid, Difusión Jurídica y Temas de Actualidad, 2008).

${ }^{55}$ Así lo reconoce la propia "Exposición de Motivos" del "Anteproyecto de Ley Orgánica por la que adapta la legislación procesal a la Ley Orgánica No 6/1985, de 1 de julio, del Poder Judicial, se plantea la reforma del recurso de casación y se generaliza la doble instancia penal": "Con esta reforma del sistema de recursos en que se concreta lo anterior se pretende, de un lado, que el Tribunal Supremo como órgano jurisdiccional superior en todos los órdenes, sea el garante de la igualdad y de la seguridad jurídica en aplicación del ordenamiento estatal, cumpliendo su función unificadora $y$, de otro, que los Tribunales Superiores de Justicia sean efectivamente la culminación de la organización judicial en el ámbito territorial de la Comunidad Autónoma". En la misma línea, véase: Desdentado Bonete, A., En torno a la posición del Tribunal Supremo en el Estado Autonómico. Una nota en la situación en el orden social, en La posición del Tribunal Supremo en el Estado Autonómico (Barcelona, Institut d'Estudis Autonòmics, 2008), p. 86.

${ }^{56}$ Ortells Ramos, M., Una nueva reforma de la casación civil española, en Práctica de Tribunales 36 (2007), pp. 5 ss.; VÁzQuez Sotelo, J. L., "Réquiem" por la mejor casación del mundo (y por otras creaciones hispanas), en Libro homenaje al Prof. Augusto M. Morello, en prensa, p. 37).

${ }^{57}$ Molins García - Atance, J., Los recursos de casación y en interés de ley de la reforma de la Ley de Enjuiciamiento Criminal, de la Ley reguladora de la Jurisdicción Contencioso-Administrativa y de la Ley de Enjuiciamiento Civil, en Diario La Ley 5 (2005), D.237, p. 944; Nieva Fenoll, J. La reforma de la labor del Tribunal Supremo y la "unificación de doctrina". Perspectivas de la introducción del modelo anglosajón en nuestro derecho, en Diario La Ley 1 (2006), D.3, p. 1.174; Ortells Ramos, M., La selección de asuntos para su acceso a la casación en Derecho español: Las técnicas de "unificación de doctrina" y de "interés casacional", en ORTElls Ramos, M. (coordinador), Los recursos ante los Tribunales Supremos en Europa / Appeals to Supreme Courts in Europe. Coloquio de Gandia y Valencia, 6, 7, y 8 de noviembre de 2008 (Madrid, Difusión Jurídica y Temas de Actualidad, 2008); Peces Morate, J. E., La jurisprudencia como guía y modelo, cit. (n. 38), p. 420. 
$\mathrm{vas}^{58}$, pretende descargar de trabajo al Tribunal Supremo. Sin embargo, para contrarrestar una eventual pérdida de la unidad del Poder judicial, se introduce el reforzamiento del papel uniformador de la jurisprudencia del Tribunal Supremo. Tan es así, que se llega a incluir un precepto dirigido a asegurar el carácter vinculante de la jurisprudencia emanada del Tribunal Supremo ${ }^{59}$.

En concreto, el aspecto más relevante de la reforma pasa por introducir un nuevo motivo para recurrir. El presupuesto para recurrir se articula en la nueva dicción del artículo 478 en función del llamado "interés casacional”, que no se vincula a la importancia, ni a la novedad, ni a la trascendencia del caso, sino a la oposición de la sentencia con la jurisprudencia o a la existencia de sentencias contradictorias con la recurrida o a la inexistencia de jurisprudencia por tratarse de normas jurídicas recientes, en una especie de adopción del modelo del "caso precedente".

Esta proyectada reforma de la casación, actualmente caducada, viene orientada hacia el otorgamiento de mayor protagonismo a la jurisprudencia en detrimento del cumplimiento de los mandatos del Poder legislativo ${ }^{60}$. La implantación del precedente vinculante, como corolario de la nomofilaxis, no parece conveniente en la realidad jurídica española, pues este sistema no sólo incide de modo directo en el sistema de fuentes del derecho, sino que tampoco parece razonable poner las mejores cabezas de la Magistratura al servicio de una función meramente nomofiláctica ${ }^{61}$. Sería tanto como hacer

${ }^{58}$ Para un análisis exhaustivo de estas posibles soluciones que permitan compatibilizar la descarga de trabajo de la Sala Primera del Tribunal Supremo y la potenciación paralela de las competencias de los tribunales superiores de justicia, recientemente examinadas en una Jornada de trabajo organizada, bajo la dirección científica, del Prof. Ramos Méndez, en la Universitat Pompeu Fabra de Barcelona (noviembre de 2008); véase, por todos: VAllespín Pérez, D., El papel de los Tribunales Superiores de Justicia ante la casación civil, en Justicia 3-4 (2005), pp. 35 ss.

${ }^{59}$ Colmenero Méndez De Luarca, M., La unificación de doctrina en el Proyecto de Ley de modificación de la casación, en Estudios de Derecho Judicial 87 (2006): La casación: unificación de doctrina y descentralización: vinculación de la doctrina del Tribunal Constitucional y vinculación de la jurisprudencia del Tribunal Supremo, p. 52; Damián Moreno, J., La reforma de la casación y la cuestión en torno al carácter vinculante de la jurisprudencia, en Diario La Ley 5 (2005) D.236, p. 940.

${ }^{60}$ Se termina por convertir al juez en legislador: Nieva FenOlL, J., La reforma de la labor del Tribunal Supremo y la "unificación de doctrina". Perspectivas de la introducción del modelo anglosajón en nuestro derecho, cit. (n. 57), p. 1.174.

${ }^{61}$ Gimeno Sendra, V. El recurso español de casación civil: Perspectiva de Reforma, en Ortells Ramos, M. (coordinador), Los recursos ante los Tribunales Supremos en Europa / Appeals to Supreme Courts in Europe. Coloquio de Gandia y Valencia, 6, 7, y 8 de noviembre de 2008 (Madrid, Difusión Jurídica y Temas de Actualidad, 2008), para quien "al Tribunal Supremo le corresponde la función nomofiláctica, lo cual no 
abandonar al alto tribunal sus funciones de juzgar y ejecutar lo juzgado, para convertir al órgano en una escuela de jurisconsultos que con vocación doctrinal, abandonasen la tutela de los derechos del justiciable.

\section{CONCLUSIÓN}

Frente a esta ruptura con la tradicional casación española, que aboga por adoptar un modelo "cuasi-anglosajón" totalmente ajeno a la cultura y tradición españolas, y que amenaza la esencia del recurso extraordinario de casación, configurándolo como un recurso nomofiláctico, en defensa de la ley, debemos mostrar nuestro desacuerdo. Si en materia de justicia se le prometen al ciudadano una serie de mecanismos de tutela a cambio de que no se tome la justicia por su propia mano, no parece nada loable engañarle después con un mecanismo como el del "interés de ley" en materia civil, que no le va reportar ningún interés directo. Un recurso meramente nomofiláctico, sin repercusión en el caso concreto, no es un modelo a seguir y se aleja, sin lógica alguna, de la clásica tutela del ius constitutionis y del ius litigatoris que es propia de una figura original como la casación española ${ }^{62}$. Es importante que el órgano de casación garantice la uniformidad de la jurisprudencia, pero no como fin en sí mismo, sino como medio a través del cual alcanzar la protección del ordenamiento jurídico. Y todo ello, además, sin olvidar que la función casacional en España siempre ha pasado por proteger el derecho propio del simple ciudadano de a pie (ius litigatoris).

Por todo lo expuesto, nos oponemos a las pretendidas reformas casacionales, que afortunadamente se encuentran suspendidas por el cambio de legislatura, que pretenden romper con el origen y tradición de la casación en España. Es cierto que el Tribunal Supremo español sufre un mal llamado "saturación", pero también es cierto, que ha sido una situación no deseada y combatida reforma tras reforma. Sin embargo, esas reformas no han acabado por destruir una figura original que sirve tanto a ius constitutionis como a ius litigatoris.

El reformar la casación española, en ningún caso, debe pasar por destruir su carácter original e histórico que la ha convertido en una de las figuras más admiradas de su entorno jurídico-cultural. De nada sirve introducir conceptos como el de "jurisprudencia vinculante" que además de ajeno al

sólo le faculta para anular aquellas resoluciones que infrinjan la Ley ordinaria, sino también a interpretarla de una manera uniforme mediante la emisión de su doctrina legal".

${ }^{62}$ Ramos Méndez, F., Enjuiciamiento Civil. Cómo gestionar los litigios civiles (Barcelona, Atelier, 2008), II, pp. 1.485 ss. 
sistema español, tiene una finalidad distinta al fin casacional tradicional español. El mantener una jurisprudencia constante o consolidada no puede sobrepasar el fin clásico que es el de resolver el fondo del asunto. Esa nota lo distinguió, desde su origen, de recursos de casación de su entorno y lo dotó de la personalidad propia de la que históricamente ha hecho gala.

Lamentablemente, este modelo de reforma puede haber dado su primer paso en la legislación chilena. Del mismo modo que el recurso español, el recurso de casación chileno nace con un espíritu jurídico en las Leyes Marianas de 1837 (mediante el "recurso de nulidad" antecedente directo de la casación) y se consagra, como tal, en el Código de Procedimiento Civil de 1902. Sin pretender recrear la historia chilena, también podemos afirmar que es una constante en Chile la finalidad nomofiláctica y uniformadora clásica de la casación, así como la persecución de la defensa del ius constitutionis y del ius litigatoris.

Ahora bien, las últimas reformas están abriendo la puerta a ese modelo más preocupado de la economía procesal y la falta de contradicción de las sentencias, adoptando figuras ajenas más propias de modelos anglosajones.

La reforma del procedimiento laboral instruye en sus artículos 483 y siguientes un recurso "para unificación de doctrina" que tiene los mismos presupuestos que el recurso para la unificación de doctrina que se introdujo en el procedimiento laboral español de 1991. A todas luces, se ha demostrado que es un instrumento que agiliza los tiempos de obtención de una resolución. Pero esa rapidez trae como contrapartida el hecho de que se vea limitado el derecho de los litigantes al solicitar como requisito que exista contradicción entre resoluciones firmes emitidas por tribunales superiores de justicia. El grado de identidad en la contradicción hace que la gran mayoría de recursos perezcan sin entrar en el fondo del asunto.

Si la reforma procesal chilena sigue el mismo camino que la española se podría, también, comenzar a abogar por un modelo de corte más anglosajón fijado en conceptos como el precedente olvidando así los casi dos cientos años de tradicional casación chilena.

Lamentablemente este camino parece haber comenzado si pensamos que la intención del legislador es introducir la unificación de doctrina a modo de "petrificación" de la jurisprudencia. Así lo reconoce un informe de la Comisión Trabajo y Previsión del Senado ${ }^{63}$, cuando en cuanto a la finalidad del recurso para unificación de doctrina expresa que "está la finalidad mayor de uniformar criterios e interpretaciones y sentar un precedente

63 "Segundo Informe de la Comisión Trabajo y Previsión del Senado", de 21 de enero de 2008, en Boletín No 4.818-13, p. 76. 
para los tribunales inferiores y las propias partes al momento de presentar sus demandas, tengan a la vista la opinión de la Corte Suprema frente a una determinada materia".

La reforma de la casación en el Proyecto de Código Procesal Civil va, todavía, más allá creando un llamado recurso extraordinario que limitando en exceso el acceso al mismo introduce un instrumento totalmente anglosajón y desconocido en nuestro entorno: el "certiorari”.

El artículo 359 del Proyecto de Código Procesal Civil conculca, todavía más, el acceso al recurso. Si la regulación de este medio de impugnación ya era de por sí restrictiva, además, debe cumplir con revestir interés público a juicio de tres ministros. Por lo que se puede desechar definitivamente un asunto simplemente por no contener un supuesto interés público. Así pues, se destierra totalmente el espíritu de la casación de servir tanto al interés público, como al privado.

Por lo menos, el legislador chileno ha tenido el acierto de eliminar la palabra casación de ese nuevo recurso extraordinario. Por lo mismo, va a cometer el error de abandonar la casación. En su reemplazo se conforma un recurso para mantener uniforme la jurisprudencia como si la Corte Suprema fuese una Escuela de jurisconsultos, en vez de un órgano jurisdiccional.

[Recibido el 28 de septiembre y aprobado el 2 de octubre de 2009].

\section{BIBLIOGRAFÍA}

Almagro Nosete, J., Situación de la casación civil en España, en Ortells Ramos, M. (coordinador), Los recursos ante los Tribunales Supremos en Europa / Appeals to Supreme Courts in Europe. Coloquio de Gandia y Valencia, 6, 7, y 8 de noviembre de 2008 (Madrid, Difusión Jurídica y Temas de Actualidad, 2008).

BaChellier, X., La technique de cassation (París, Dalloz, 2003).

BorÉ, J. L., La cassation en matière civile (París, Dalloz, 2003).

CADIET, L., El sistema de la casación francesa, en ORTElls Ramos (coordinador), Los recursos ante los Tribunales Supremos en Europa / Appeals to Supreme Courts in Europe. Coloquio de Gandia y Valencia, 6, 7 y 8 de noviembre de 2008 (Madrid, Difusión Jurídica y Temas de Actualidad, 2008).

Calamandrei, P. La casación civil (traducción de Sentís Melendo, Buenos Aires, 1945).

Colmenero Méndez De Luarca, M., La unificación de doctrina en el Proyecto de Ley de modificación de la casación, en Estudios de Derecho Judicial 87 (2006): La casación: unificación de doctrina y descentralización: vinculación de la doctrina del Tribunal Constitucional y vinculación de la jurisprudencia del Tribunal Supremo.

Chiovenda, J., Principios del Derecho procesal civil (traducción de J. Casáis Santaló, Madrid, Reus, 1925), II. 
DAmián MoReno, J., La reforma de la casación y la cuestión en torno al carácter vinculante de la jurisprudencia, en Diario La Ley 5 (2005).

De Castro Fernández, J., La reforma de la casación, en Revista Jurídica de Catalunya 4 (1985).

De La Plaza, M., Derecho procesal civil español, en Revista de Derecho Privado 1 (Madrid 1951).

Desdentado Bonete, A., En torno a la posición del Tribunal Supremo en el Estado Autonómico. Una nota en la situación en el orden social, en La posición del Tribunal Supremo en el Estado Autonómico (Barcelona, Institut d'Estudis Autonòmics, 2008).

Fairén Guillén, V., Estudio externo de la Ley de Enjuiciamiento Civil de 1855, en Temas del ordenamiento procesal (Madrid, Tecnos, 1969), II.

FAIRÉN GuILLÉN, V., La doctrina legal y el control de los hechos en la casación civily laboral española, en Temas del ordenamiento procesal (Madrid, Tecnos, 1969).

FernÁndez Rodríguez, A., La nueva ordenación de los recursos. Especial estudio del recurso de casación, en Jornadas sobre la Reforma de la Ley de Enjuiciamiento Civil (Madrid, Consejo General del Poder Judicial, 1985).

Fernández, M. A., Derecho procesal civil (con de la Oliva, J., Madrid, Centro de Estudios Ramón Areces, 1995), II.

Garberí llobregat, J. - González-Cuéllar Serrano, N., Apelación y casación en el proceso civil (Madrid, Colex, 1994).

GaRCía CELAÁ, B., El principio de unidad jurisdiccional. Las reformas en el recurso de casación, los consejos territoriales y la justicia de proximidad en relación con la jurisdicción social, en Estudios de Derecho Judicial 90 (2006): Poder Judicial y unidad jurisdiccional en el Estado autonómico.

GénY, F. Método de interpretación y fuentes en Derecho privado positivo (Madrid, Reus, 1925).

Gimeno Sendra, V. (coordinador), El recurso civil de casación, el Tribunal Supremo, su doctrina legal y el recurso de casación, en GIMENO SENDRA, V. (coordinador), Estudios en Homenaje del Profesor Almagro Nosete (Madrid, Iustel, 2007).

Gimeno Sendra, V. El recurso español de casación civil: Perspectiva de Reforma, en Ortells Ramos, M. (coordinador), Los recursos ante los Tribunales Supremos en Europa / Appeals to Supreme Courts in Europe. Coloquio de Gandia y Valencia, 6, 7, y 8 de noviembre de 2008 (Madrid, Difusión Jurídica y Temas de Actualidad, 2008).

Gimeno SENDra, V., El recurso extraordinario por infracción procesal, en Picó I JunOY (director), Presente y futuro del proceso civil (Barcelona, Bosch, 1998).

Gimeno Sendra, V., Derecho procesal civil, I: El Proceso de declaración. Parte general (Madrid, Colex, 200).

Gimeno Sendra, V., El recurso civil de casación, en Gimeno Sendra, V. (coordinador), El Tribunal Supremo, su doctrina legal y el recurso de casación. Estudios en Homenaje del Profesor Almagro Nosete (Madrid, Iustel, 2007).

Gimeno Sendra, V., El recurso de amparo judicial y el anteproyecto de Ley de Enjuiciamiento Civil, en Diario La Ley 6 (1997).

Gimeno Sendra, V., El recurso español de casación civil: Perspectiva de Reforma, en Ortells Ramos, M. (coordinador), Los recursos ante los Tribunales Supremos en Europa / Appeals to Supreme Courts in Europe. Coloquio de Gandia y Valencia, 6, 
7, y 8 de noviembre de 2008 (Madrid, Difusión Jurídica y Temas de Actualidad, 2008).

Gómez Orbaneja, E. - Herce Quemada, V., Derecho procesal civil (Madrid, Artes Gráficas y Ediciones, 1979).

GotTwald, P., El recurso ante el Tribunal Supremo Federal alemán tras la reforma de 2001 (versión abreviada), en Ortells Ramos, M. (coordinador), Los recursos ante los Tribunales Supremos en Europa / Appeals to Supreme Courts in Europe. Coloquio de Gandia y Valencia, 6, 7, y 8 de noviembre de 2008 (Madrid, Difusión Jurídica y Temas de Actualidad, 2008).

Guasch Fernández, S., El hecho y el Derecho en la casación civil (Barcelona, Bosch, 1998).

JiméNez Fortea, F. J., El recurso de casación para la unificación de la doctrina laboral: problemas fundamentales (Valencia, Tirant lo Blanch, 1999).

JiMÉNEZ FORTEA, La casación para la unificación de doctrina laboral: instituciones afines en Derecho comparado, en Revista General de Derecho 649-650 (1998).

MÁLAGa DíEguez, F., Los recursos de casación y extraordinario por infracción procesal en la jurisprudencia del Tribunal Superior de Justicia de Cataluña, en Justicia 1-3 (2003).

Manresa y Navarro, J. M. Comentarios a la Ley de Enjuiciamiento Civil (Madrid, Instituto Editorial Reus, 1895), VII.

ManResa, J. M., Observaciones sobre el recurso de casación en España, en Revista General de Legislación y Jurisprudencia 16 (1960).

Martínez Emperador, R., La nueva casación social. Puntos críticos, en Actualidad Laboral 16 (1992).

Martínez-Calcerrada y Gómez, L. La nueva casación civil. Estudio de la Ley 10/1992 de 30 de abril (Madrid, Civitas, 1993).

Molins García - ATANCE, J., Los recursos de casación y en interés de ley de la reforma de la Ley de Enjuiciamiento Criminal, de la Ley reguladora de la Jurisdicción ContenciosoAdministrativa y de la Ley de Enjuiciamiento Civil, en Diario La Ley 5 (2005).

Montero Aroca, J. - Flors Matíes, J., Los recursos en el proceso civil (Valencia, Tirant lo Blanch, 2001).

Montero Aroca, J. - Flors Matíes, J., Los recursos en el proceso civil (Valencia, Tirant lo Blanch, 2001).

Montero Aroca, J., La Ley de Enjuiciamiento Civil de 1855. La consolidación del proceso común, en Ensayos de Derecho procesal (Barcelona, Bosch, 1996).

Montesquieu, Ch. L., Del espiritu de las leyes (traducción de M. Blázquez y P. de Vega, Madrid, Sarpe, 1984).

Morales Morales, F., El recurso extraordinario por infracción procesal, en Diario La Ley 5 (2001).

Morello, A. M., La casación. Un modelo eficiente (La Plata, Librería Editora Platense, 2000).

Moreno Catena, V., Los recursos extraordinarios por infracción procesal y casación, en Gimeno Sendra, V. - Moreno Catana, V. - Cortés Domínguez, V., Derecho procesal civil. Parte general (2a edición, Madrid, Colex, 2003).

Morón Palomino, M., La nueva casación civil (Madrid, Colex, 2001).

Morón Palomino, M., Precisiones y significación constitucional del recurso de casación, en Diario La Ley 5 (2004). 
Muñoz Jiménez, F. J., Del recurso de casación por infracción procesal, en Comentarios a la nueva Ley de Enjuiciamiento Civil, II.

Nieva Fenoll, J. La reforma de la labor del Tribunal Supremo y la "unificación de doctrina". Perspectivas de la introducción del modelo anglosajón en nuestro derecho, en Diario La Ley 1 (2006).

Nieva Fenoll, J., El recurso de casación civil (Ariel, Barcelona, 2003).

NiEVA FenOlL, J., La casación en materia social ("ordinaria" y por unificación de doctrina): la decadencia de la casación, en Relaciones Laborales 15-16 (2004).

Ortells Ramos, M., Derecho jurisdiccional (Pamplona, Aranzadi, 2004).

Ortells Ramos, M., El Tribunal Supremo Español: Un Tribunal en busca de identidad, en Gimeno Sendra, V. (coordinador), El Tribunal Supremo, su doctrina legal y el recurso de casación. Estudios en Homenaje del Profesor Almagro Nosete (Madrid, Iustel, 2007).

Ortells Ramos, M., La selección de asuntos para su acceso a la casación en Derecho español: Las técnicas de "unificación de doctrina" y de "interés casacional", en ORTELLS Ramos, M. (coordinador), Los recursos ante los Tribunales Supremos en Europa I Appeals to Supreme Courts in Europe. Coloquio de Gandia y Valencia, 6, 7, y 8 de noviembre de 2008 (Madrid, Difusión Jurídica y Temas de Actualidad, 2008).

Ortells Ramos, M., Una nueva reforma de la casación civil española, en Práctica de Tribunales 36 (2007).

Ortells Ramos, M.,La selección de asuntos para su acceso a la casación en Derecho Español: Las técnicas de "unificación de doctrina" y de "interés casacional", en ORTELLS Ramos, M. (coordinador), Los recursos ante los Tribunales Supremos en Europa I Appeals to Supreme Courts in Europe. Coloquio de Gandia y Valencia, 6, 7, y 8 de noviembre de 2008 (Madrid, Difusión Jurídica y Temas de Actualidad, 2008).

Peces Morate, J. E., La jurisprudencia como guía y modelo en la función de juzgar, en Gimeno Sendra, V. (coordinador), El Tribunal Supremo, su doctrina legal y el recurso de casación. Estudios en Homenaje al Prof. Almagro Nosete (Madrid, Iustel, 2007).

Prieto-Castro, L., Tratado de Derecho procesal civil (Pamplona, Aranzadi, 1985).

Puignaire Hernández, J. M., Comentarios a la Ley de reforma urgente del procedimiento civil (Barcelona, Acervo, 1985).

Ramos Méndez, F., ¿Qué hacemos con el Tribunal Supremo? en Gimeno Sendra, V. (coordinador), El Tribunal Supremo, su doctrina legal y el recurso de casación. Estudios en Homenaje del Profesor Almagro Nosete (Madrid, Iustel, 2007).

Ramos Méndez, F., Enjuiciamiento civil (Barcelona, Bosch, 1997).

Ramos Méndez, F., Enjuiciamiento Civil. Cómo gestionar los litigios civiles (Barcelona, Atelier, 2008), II.

Rodríguez Bahamonde, R., El recurso extraordinario por infracción procesal, en Alonso-Cuevillas (coordinador), Instituciones del nuevo proceso civil. Comentarios sistemáticos a la Ley 1/2000 (Barcelona, Economist \& Jurist, 2000).

Rousseau, J. J. El contrato social (traducción de J. Carrier, Barcelona, Edicomunicación, 1994).

SaAvedra Gallo, P., Comentario al artículo 466 de la nueva LEC, en Gómez DE Liaño, F. (coordinador), Ley de Enjuiciamiento Civil (Ley 1/2000) (Oviedo, Forum, 2000).

SÁnChez Albarrán, O., La eficiencia de la futura reforma de la casación civil española. 
Una aproximación desde la óptica del análisis económico del derecho, en Revista Vasca de Derecho Procesal y Arbitraje 3 (2007).

SANTOS BRIZ, J., El recurso de casación. Su reforma por Ley 34/1984, de 6 de agosto, e incidencia de la misma en las reclamaciones derivadas de accidentes de circulación, en Revista de Derecho Privado (1985).

Serra Domínguez, M. El recurso de casación, en El mismo (coordinador), Comentarios a la reforma de la Ley de Enjuiciamiento Civil (Ley 34/1984, de 6 de agosto) (Madrid, 1985).

Serra Domínguez, M., El recurso de casación en la LEC 1/2000, en Revista Jurídica de Catalunya 4 (2001).

Tovar Morais, A., El recurso de casación civil (Ley 6 de agosto de 1984) (Pamplona, Aranzadi, 1985).

VAllespín Pérez, D., El modelo constitucional de juicio justo en el ámbito del proceso civil (Barcelona, Atelier, 200).

Vallespín Pérez, D., El papel de los tribunales superiores ante la casación civil, en Gimeno Sendra, V. (coordinador), El Tribunal Supremo, su doctrina legal y el recurso de casación, en Estudios en Homenaje del Profesor Almagro Nosete (Madrid, Iustel, 2007).

VAllespín PÉREz, D., El papel de los tribunales superiores de justicia ante la casación civil, en Justicia 3-4 (2005).

Vallespín Pérez, D., El papel de los Tribunales Superiores de Justicia ante la casación civil, en Gimeno Sendra, V. (coordinador), El Tribunal Supremo, su doctrina legal y el recurso de casación. Estudios en Homenaje del Profesor Almagro Nosete (Madrid, Iustel, 2007).

Vallespín Pérez, D., El papel de los Tribunales Superiores de Justicia ante la casación civil, en Justicia 3-4 (2005).

VAllespín PÉREZ, D., Los nuevos retos del derecho a la tutela judicial efectiva en el proceso civil (Barcelona, Cims Editorial, 2009).

VÁzQuez Sotelo, J. L., Réquiem por la mejor casación del mundo (y por otras creaciones hispanas), en Libro homenaje al Prof. Augusto M. Morello, en prensa).

VÁzQuez Sotelo, J. L., El modelo español de casación (Configuración histórica y evolución legislativa), en Scritti in onore di Elio Fazzalari (Milano, Giuffrè, 1993).

VÁzQuez Sotelo, J. L., La casación civil (revisión crítica) (Barcelona, Ediser, 1979).

VÁzquez Sotelo, J. L., Rasgos definidores de la casación civil española, en Revista de Derecho Procesal (1974).

Vicente Chamorro, J., El recurso de casación en materia civil (Pamplona, Aranzadi, 1991). 
